\title{
Pedicle Screw Surgery in the UK and Ireland: A Questionnaire Study
}

\author{
P.S.D. Patel ${ }^{1}$, E.M. Aspinwall ${ }^{1}$, A.J. Fennell ${ }^{2}$, S.G. Trotman ${ }^{2}$, D.E.T. Shepherd ${ }^{1}{ }^{*}$ and \\ D.W.L. Hukins ${ }^{1}$ \\ ${ }^{I}$ School of Mechanical Engineering, University of Birmingham, Edgbaston, Birmingham, B15 2TT, UK \\ ${ }^{2}$ Surgicraft Ltd., 16 The Oaks, Clews Road, Redditch, Worcestershire, B98 7ST, UK
}

\begin{abstract}
Pedicle screw (PS) malpositioning rates are high in spine surgery. This has resulted in the use of computed navigational aids to reduce the rate of malposition; but these are often expensive and limited in availability. A simple mechanical device to aid PS insertion might overcome some of these disadvantages. The purpose of this study was to determine the demand and design criteria for a simple device to aid PS placement, as well as to collect opinions and experiences on PS surgery in the UK and Ireland. A postal questionnaire was sent to 422 spinal surgeons in the UK and Ireland. 101 questionnaires were received; 67 of these (16\% of total sent) contained useful information. $78 \%$ of surgeons experienced problems with PS placement. The need for a simple mechanical device to aid PS placement was expressed by $59 \%$ of respondent surgeons. The proportion of respondents that inserted PSs in the cervical spine was 14\%; PSs are mainly inserted in the thoracic, lumbar and sacral spine, but potential exists for a PS placement aid for the cervical and thoracic spine. From the experiences of these 67 surgeons, there is evidence to suggest that surgeons would prefer a pedicle aid that is multiple use, one-piece, hand-held, radiolucent, unilateral and uses the line of sight principle in traditional open surgery. Based on the experiences of 67 surgeons, there is evidence to suggest that computed navigational aids are not readily used in PS surgery and that a simple mechanical device could be a better option. This paper provides useful data for improving the outcomes of spinal surgery.
\end{abstract}

Keywords: Navigation in surgery, Osteoporosis, Pedicle screw placement, Questionnaire.

\section{INTRODUCTION}

This study aimed to determine the demand and design criteria for a potential simple device to aid pedicle screw (PS) placement, as well as to collect opinions and experiences on PS surgery in the UK and Ireland. Complications associated with PS surgery can be screwrelated (e.g. breakage or loosening) or a surgical complication (e.g. pedicle fracture or nerve root injury) [1, 2]. Screw malpositioning is a problem with approximately $20 \%$ implanted inaccurately by experienced surgeons [3]. In treating neuromuscular scoliosis $27 \%$ of PSs were placed outside the pedicle [4]. The problem has resulted in the use of navigational aids to reduce the rate of malposition [5]. However, these navigational aids are often expensive, limited in availability and present problems in some circumstances [6]. A simple mechanical device to aid PS insertion might overcome some of these disadvantages.

\section{MATERIALS AND METHODS}

A questionnaire was designed in consultation with a statistician who has experience in questionnaire design (E.M.A) and industrial partners (A.J.F and S.G.T). In March 2007 , the postal questionnaire (11 questions) was sent to 422 surgeons on a list provided by Surgicraft Ltd. (Redditch,

*Address correspondence to this author at the School of Mechanical Engineering, University of Birmingham, Edgbaston, Birmingham, B15 2TT, UK; Tel: +44 (0)121 414 4266; Fax: +44 (0)121 414 3958;

E-mail: d.e.shepherd@bham.ac.uk
UK); the list accounted for the majority of surgeons known to perform spinal surgery in the UK and Ireland. The list had been assembled by Surgicraft Ltd. using information purchased from a medical data company, in addition to using the feedback information from sales representatives of Surgicraft Ltd. Some of the survey questions were designed to generate a single answer; others were designed to encourage an open answer or to produce multiple answers. Upon receipt of the completed questionnaires, any similar statements from different surgeons were grouped together. Frequencies and percentages were calculated for the categorical variables. For Question 1 and Question 6, Chisquared testing [7] was used to test for any association between surgeon speciality (i.e. orthopaedic surgeon or neurosurgeon) and question response (i.e. Yes or No); statistical comparisons were made using MINITAB ${ }^{\circledR}$ Release 15 Statistical Software (Minitab Inc., Pennsylvania, USA). The significance level was set at 0.05 for all tests. The motivation for comparing responses from orthopaedic surgeons and neurosurgeons was to identify if there is a difference in opinion between the two surgical groups when answering Question 1 and Question 6.

\section{RESULTS}

\section{Response Rate}

101 questionnaires (24\%) were returned, consistent with other surgical surveys [2, 8-10]; 67 of these (16\% of total sent) contained useful information, which form the basis of the results reported in this paper. The 67 respondents 


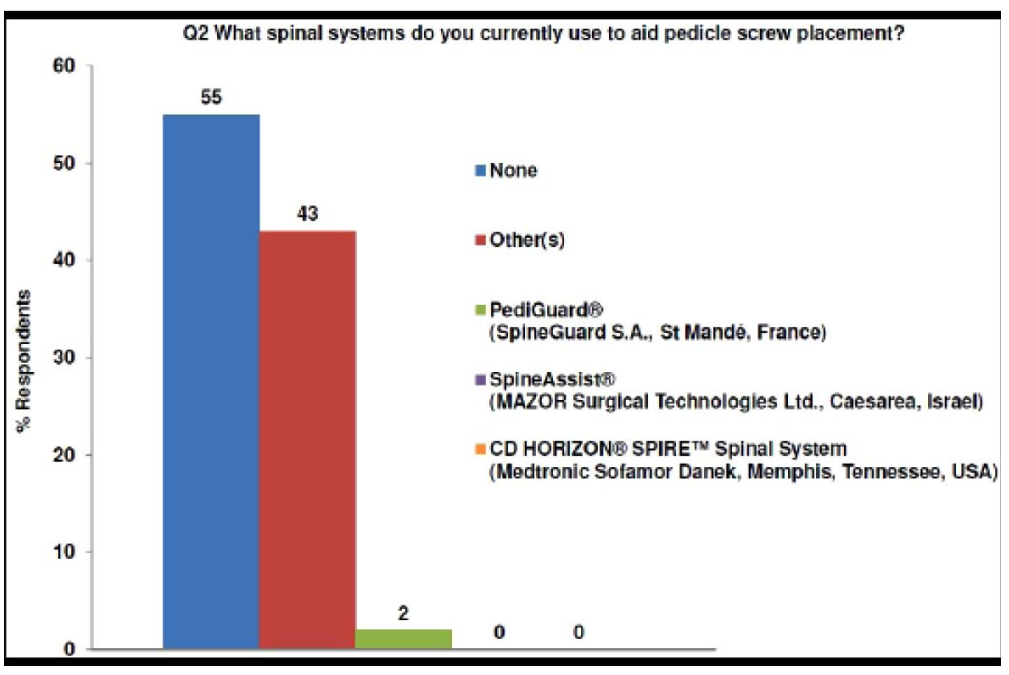

Fig. (1). Spinal systems used by the respondents to aid pedicle screw placement (as specified in Question 2).

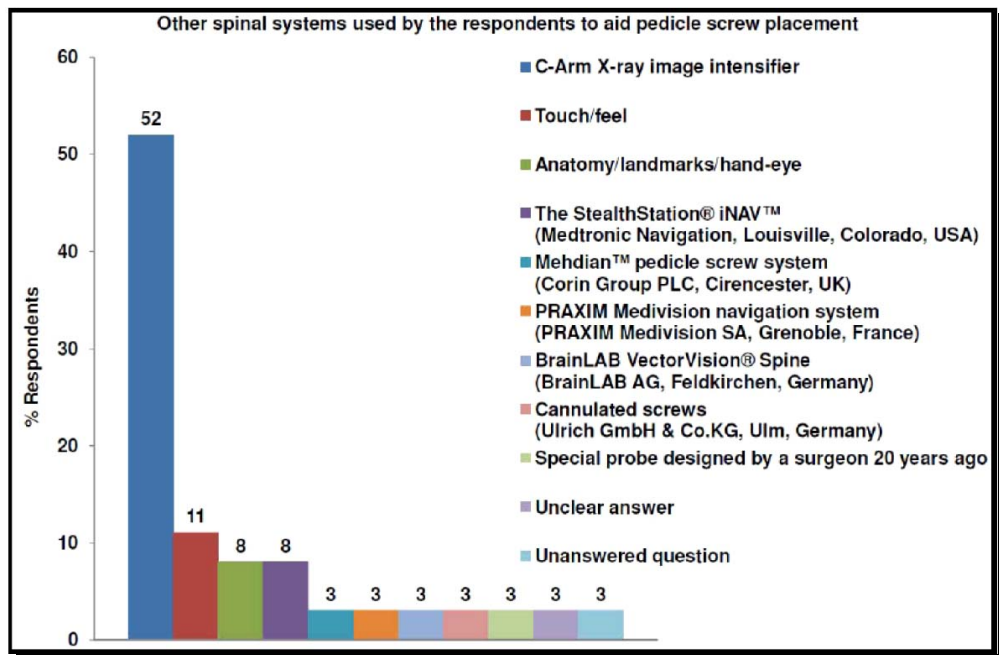

Fig. (2). Breakdown of "Other(s)" spinal systems used by the respondents to aid pedicle screw placement (follow-on from Question 2).

comprised of the following surgical groups: 50 orthopaedic surgeons, 14 neurosurgeons, 1 spinal surgeon and 2 unanswered/are not any of the above.

\section{Q1. Do you Think There is a Need for a Simple Device to Aid PS Placement? Please Give Reasons for your Answer}

The majority of respondents $(59 \%)$ were in favour of a simple device to aid PS placement; $37 \%$ were not in favour; 4\% did not answer Question 1.

Respondents in favour of a simple device had a relatively high experience of malpositioning. The reduced risk of neurological/vascular complications, reduced incidence of pedicle breach, reduced X-ray exposure, increased confidence, increased accuracy, use as a training tool, use as a supplementary aid and an increased rate of correct screw placement were considered potential benefits. Emphasis was placed on using a simple device to correctly position screws in seriously deformed/degenerated spines. The device was also favoured for revision surgery in the thoracic and the cervical spine.

Respondents not in favour believed that imaging techniques and anatomical knowledge are sufficient aids to PS surgery. Other comments included: the devices not having proper track records; the belief that they already exist (but offer no advantage); the belief that navigation systems are cumbersome and expensive. It was also noted that, in many cases, the pedicle is breached deliberately. Furthermore, respondents explained that blind placement with the aid of a device could lead to the use of PSs by surgeons unfamiliar with the anatomy, and therefore unfamiliar with the clinical indications.

For Question 1, the respondent orthopaedic surgeons answered $61 \%$ Yes and $39 \%$ No; the respondent neurosurgeons answered $62 \%$ Yes and $38 \%$ No. No significant difference $(p>0.05)$ was found between the neurosurgeons and orthopaedic surgeons and whether or not they think there is a need for a simple device to aid PS placement.

\section{Q2. What Spinal Systems do you Currently use to Aid PS Placement?}

The majority of respondents (55\%) did not use any systems to aid PS placement; $2 \%$ used the systems specified in the question (Fig. 1); $43 \%$ used other systems (Fig. 2). The majority using "Other" systems $(52 \%)$ used C-Arm Xray image intensifiers. 
Table 1. Good Features and Limitations/Shortfalls of the Spinal Systems used by the Respondents (Question 3)

\begin{tabular}{|c|c|c|}
\hline Spinal System Used & Good Features & Limitations \& Shortfalls \\
\hline \multirow[t]{6}{*}{$\begin{array}{l}\text { PediGuard® } \\
\text { (SpineGuard S.A., St Mandé, France) }\end{array}$} & Likened as a pedicle screw "parktronic" system & Noisy \\
\hline & Easy to use & Different feel to normal pedicle finder \\
\hline & & Sensitivity problems \\
\hline & & Expensive \\
\hline & & Delicate \\
\hline & & Slightly short probe \\
\hline \multirow[t]{8}{*}{$\begin{array}{l}\text { C-Arm X-ray } \\
\text { Image Intensifier }\end{array}$} & Quick & $\mathrm{X}$-ray dose to patient and surgical team \\
\hline & Available at all hospitals & Difficult with scoliosis \\
\hline & Good visualisation. & Need to move image intensifier \\
\hline & $\begin{array}{l}\text { Helps with ideal placement \& most appropriate } \\
\text { angles in the lumbar/thoracic spine }\end{array}$ & $\begin{array}{l}\text { Does not provide a 3D image; risk of } \\
\text { encroaching on the spinal canal }\end{array}$ \\
\hline & Easily adjustable & Difficult with small pedicles \\
\hline & Portable & Occasional image quality problems \\
\hline & & Inexperienced staff \\
\hline & & Learning curve for junior staff \\
\hline Touch/feel & Increased certainty of placement & Does not provide $100 \%$ certainty \\
\hline $\begin{array}{l}\text { Special probe designed } \\
\text { by a surgeon } 20 \text { years ago }\end{array}$ & $\begin{array}{l}\text { Safe method } \\
\text { Inexpensive }\end{array}$ & Not good for porotic bone \\
\hline $\begin{array}{c}\text { Mehdian } \\
\text { pedicle screw system } \\
\text { (Corin Group PLC, Cirencester, UK) }\end{array}$ & $\begin{array}{l}\text { Simple } \\
\text { Easy to use }\end{array}$ & \\
\hline \multirow{2}{*}{$\begin{array}{l}\text { The StealthStation }{ }^{\circledR} \text { iNAVTM } \\
\text { (Medtronic Navigation, Louisville, Colorado, USA) }\end{array}$} & Accurate & Increased surgery time \\
\hline & Provides security & Heavy reliance on imaging \\
\hline \multirow{3}{*}{$\begin{array}{l}\text { PRAXIM Medivision navigation system } \\
\text { (PRAXIM Medivision SA, Grenoble, France) }\end{array}$} & Provides 3D images & Long set-up and training time \\
\hline & Accurate & Bulky \\
\hline & & Complex equipment; prone to breaking down \\
\hline $\begin{array}{c}\text { BrainLAB } \\
\text { VectorVision }{ }^{\circledR} \text { Spine (BrainLAB AG, Feldkirchen, } \\
\text { Germany) }\end{array}$ & Easy to use & No real-time pictures \\
\hline $\begin{array}{c}\text { Cannulated screws } \\
\text { (Ulrich GmbH \& Co.KG, Ulm, Germany) }\end{array}$ & Easy to insert using a guide wire & \\
\hline
\end{tabular}

Table 2. Problems Encountered by the Questionnaire Respondents Whilst Undertaking Pedicle Screw Surgery (Question 6)

\begin{tabular}{|c|c|}
\hline Problem with Pedicle Screw Surgery & Examples of Surgeons' Remarks \\
\hline \multirow[t]{2}{*}{ Treating scoliosis } & Beware the degenerative scoliosis! Either too medial or too lateral. Dependent on vertebral rotation \\
\hline & Adult scoliosis \\
\hline \multirow[t]{2}{*}{ Locating the pedicle } & Defining the pedicle using an image intensifier can be very difficult \\
\hline & Missing pedicle numbers \\
\hline \multirow[t]{2}{*}{ Breaching of the pedicle walls } & Pedicle cortex breach \\
\hline & $\begin{array}{c}\text { Medial (occasionally), inferior (rare) and lateral (infrequent) breach. Nerve root tension is relieved } \\
\text { by removal and re-directing of screw }\end{array}$ \\
\hline Perforating the vertebral body wall & $\begin{array}{l}\text { Commonest error encountered is when surgeons have gone too directly anterior in L5 or S1, } \\
\text { perforating the lateral vertebral body wall and hitting the descending nerve root }\end{array}$ \\
\hline
\end{tabular}


Table 2. cont...

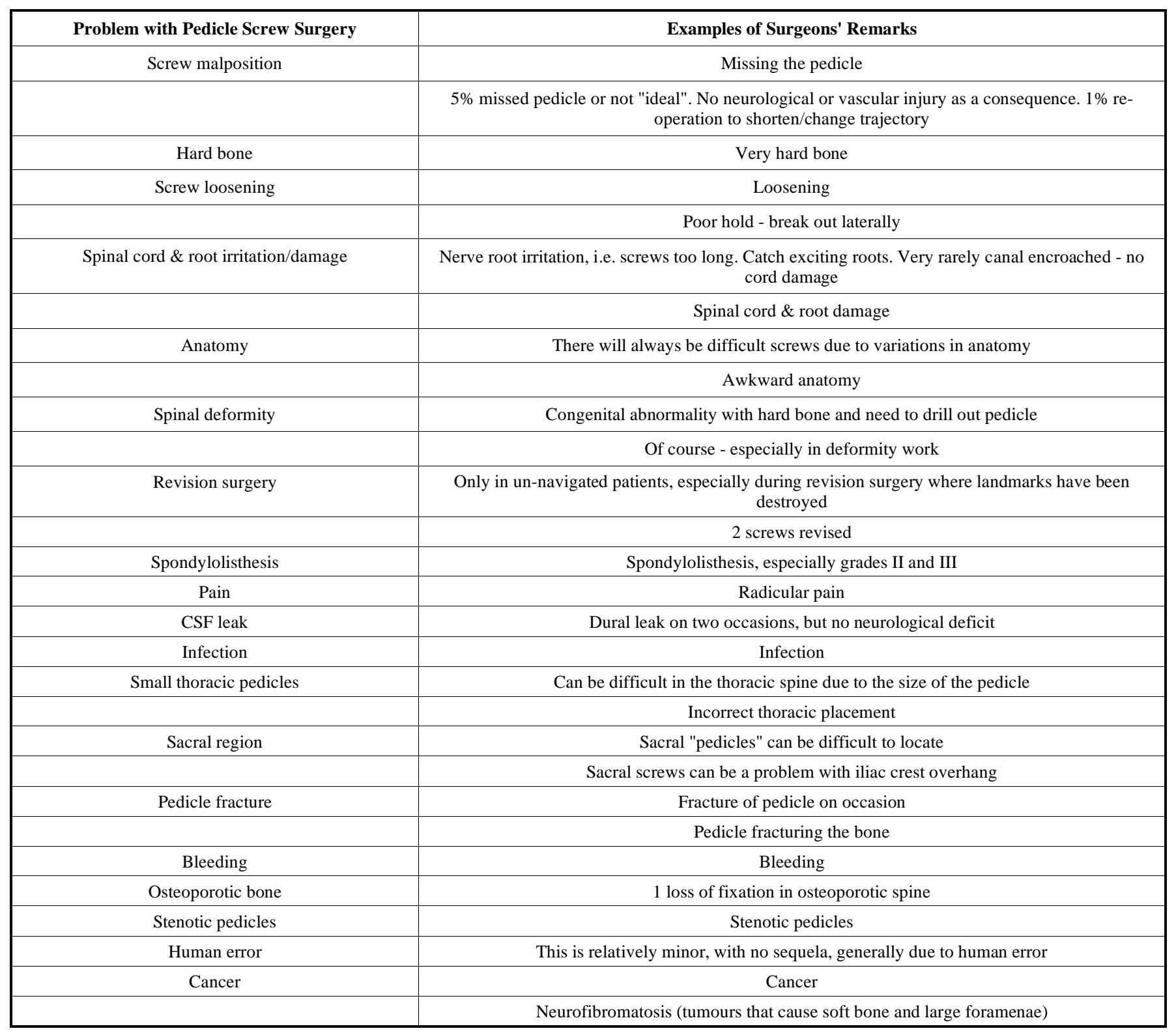

Q3. What are the good Features and Limitations/Shortfalls of these Particular Spinal Systems that you Use?

Most respondents found the specified systems easy to use, safe and accurate (Tables 1). The 3D images provided by some systems, e.g. PRAXIM Medivision navigation system (PRAXIM Medivision SA, Grenoble, France), were considered a major asset. Common limitations were the associated learning time and increased surgery time, as well as high cost and the inability to deal with all spinal conditions.

\section{Q4. What is your Idea of the 'Perfect' PS Path/Entry Point/Trajectory for the Positioning of a PS?}

Respondents either provided general or region-based descriptions/sketches for PS placement, which are described below.

\section{General Comments}

The ideal positioning technique would have the following characteristics:

- Using the facet joint bone as a landmark to expose the pedicle;

- Using lateral plane and anterior-posterior plane X-ray films (when 2 screws are inserted at the same level), to direct the screw medially to the "projected" point of intersection with the opposite side, in the anterior third of the vertebral body;

- $\quad$ Tailoring each screw trajectory to the anatomy of the spinal element(s) captured by the screw;

- Choosing a screw path that does not involve any secondary soft tissues; 
- Placing the screw within the cortical margins of the pedicle, without breaching the bone (less important in cases such as extradural tumours);

- Placing the screw parallel to the superior end-plate, such that the screw reaches just short of the anterior vertebral body.

The following characteristics summarise what should be avoided during ideal PS positioning:

- Using a lateral approach through the lateral pedicle wall;

- Allowing screw penetration through the anterior cortex (except in exceptional circumstances e.g. gross osteoporosis);

- Allowing full triangulation of two PSs inserted at the same level, especially in kyphosis.

\section{Cervical Spine}

Respondents noted that the entry point for PSs in the cervical spine are as for lateral mass screws, but directed medially. For $\mathrm{C} 2$, the mid-cervical region and $\mathrm{C} 6 / \mathrm{C} 7,25^{\circ}$ $30^{\circ}, 10^{\circ}-15^{\circ}$ and $0^{\circ}$, respectively, lateral-medial screw angulation was recommended.

\section{Thoracic Spine}

Extra-pedicle to intra-pedicle approaches were not recommended in the thoracic spine. Respondents advised that screws should be placed starting from a medial position, aiming straight down the pedicle axis. A common entry point was identified; between the base of the transverse process and laminar groove to the upper border of the transverse process. For T1-T4, T5-T10 and T11/T12, $10^{\circ}-20^{\circ}, 10^{\circ}$ and $0^{\circ}-10^{\circ}$, respectively, lateral-medial angulation was recommended. For T11/T12, respondents also advised that the mammillary process should be amputated and that the screw should be directed anteriorly.

\section{Lumbar Spine}

As a screw insertion point, respondents advised using the mid-point of the mammillary process, on the transverse process, to the facet of the lumbar vertebra. They also recommended screw placement down the centre of the pedicle and just beyond halfway through the vertebral body, as seen on a lateral plane X-ray. For non-fusions of the lumbar spine, the Wiltse minimally invasive approach was recommended. For fusions of the lumbar spine, the standard mid-line approach was recommended.

Respondents suggested the following screw trajectories for the ideal screw placement at different levels of the lumbar spine: for L2/L3 - slightly cephalad, for L4 horizontal, for L5 - slightly caudal, plus a $15^{\circ}$ lateral-medial screw angulation (to give an oblique path across the vertebral body). They noted that the postero-lateral approach to PS insertion increases screw pullout strength, and that $80 \%$ screw penetration is ideal for the lumbar spine.

\section{The Sacrum}

At the S1 level, respondents advised that the PS should ideally project in an antero-medial direction. To achieve good purchase, it was advised that the screw should engage with the anterior cortex of the sacral vertebra. A $25^{\circ}-35^{\circ}$ lateral-medial screw angulation at L5/S1 was also recommended.

\section{Q5. In which Regions of the Human Spine have you Inserted PSs?}

The majority of respondents have inserted PSs in more than one region of the human spine. The proportion of respondents that have inserted PSs in the cervical spine was $14 \% ; 28 \%$ have inserted PSs in the thoracic spine; $30 \%$ have inserted PSs in the lumbar spine; $28 \%$ have inserted PSs in the sacral spine.

\section{Q6. Have you Experienced any Problems with PS Placement in Patients? If Yes, Please Specify the Problems}

Most respondents (78\%) had experienced problems listed in Table 2; $16 \%$ did not have any problems with PS placement; 6\% did not answer Question 6. The respondent orthopaedic surgeons answered $87.5 \%$ Yes and $12.5 \%$ No; the respondent neurosurgeons answered $71 \%$ Yes and $29 \%$ No. No significant difference ( $p>0.05$ ) was found between the neurosurgeons and orthopaedic surgeons and whether or not they had experienced problems with PS placement.

Q7. (a) In your Opinion, Which Regions of the Human Spine Would Benefit from a Simple Device to aid PS Placement?

The percentage of respondents in favour of a simple device for a particular spinal region were: $24 \%$ for the cervical spine, $29 \%$ for the thoracic spine, $20 \%$ for the lumbar spine, $16 \%$ for the sacral spine; $3 \%$ did not think a device was necessary; $1 \%$ did not know; $7 \%$ did not answer Question 7 and/or had no view.

\section{Q7. (b) Why do you think this?}

\section{Cervical Region}

The small pedicles make it difficult to define the anatomy and judge the surface landmarks of this region. The wrong trajectory of PS placement can easily lead to spinal cord/vascular injury, which is why lateral mass plates are often preferred, especially in the lower region.

\section{Thoracic Region}

Respondents highlighted the thoracic spine as the most difficult region. They felt there was more need for a pedicle aid in the mid to upper thoracic spine, because of the higher risk to neurological structures. One respondent commented that the T4-T8 region may have very small pedicles and the "numerous tissue planes and density differences make realisation with image intensification very difficult." Respondents noted that the risk of spinal cord injury is increased further in the case of scoliosis. Another respondent, in favour of an aid, noted that surgeons often prefer to be safe and place screws "too laterally" in the thoracic spine, increasing the risk of screw pullout.

\section{Lumbar Region}

Respondents noted that screw malpositioning carries less risk of neurovascular injury in the lumbar spine; because the 


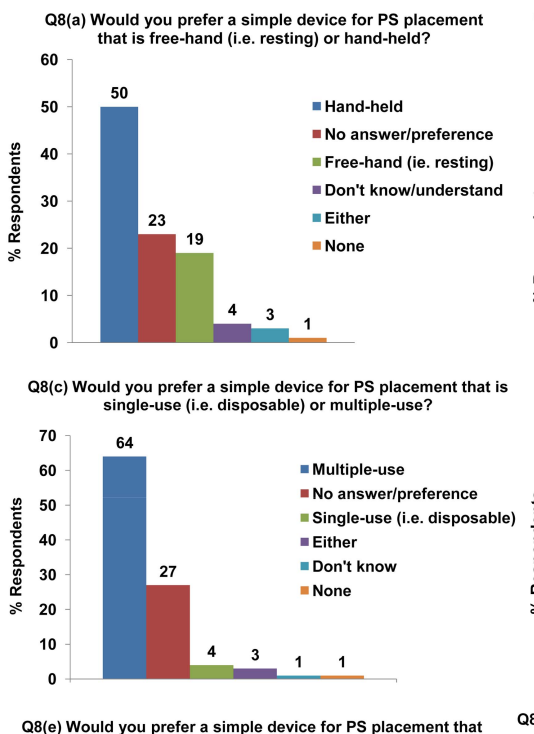
Q8(b) Would you prefer a simple device for PS placement that
radiolucent (transparent to X-rays) or radiopaque?
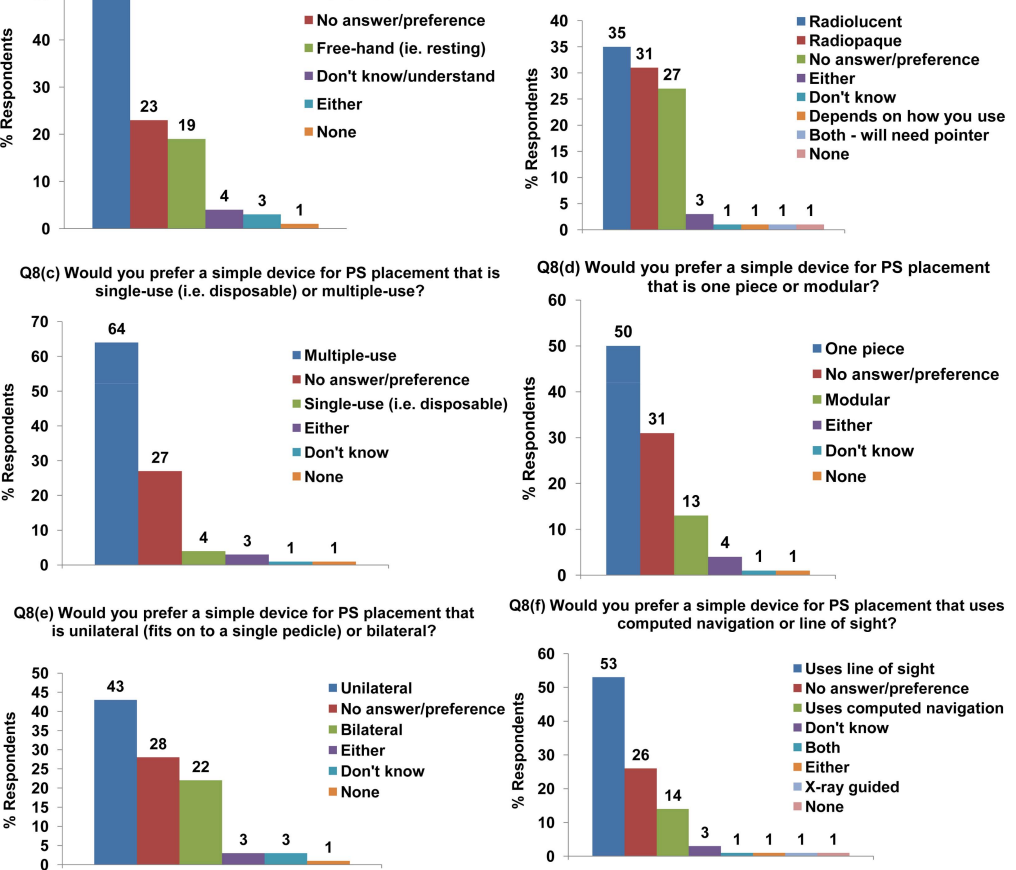

Q8(d) Would you prefer a simple device for PS placement 60 that is one piece or modular?

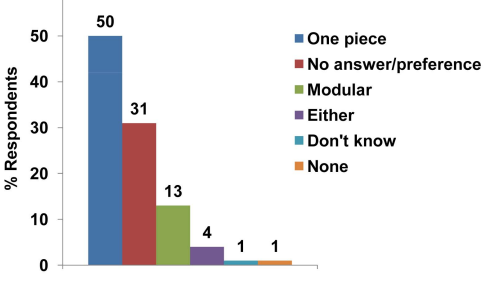

Q8(f) Would you prefer a simple device for PS placement that uses (f) Would you prefer a simple device for PS placement?
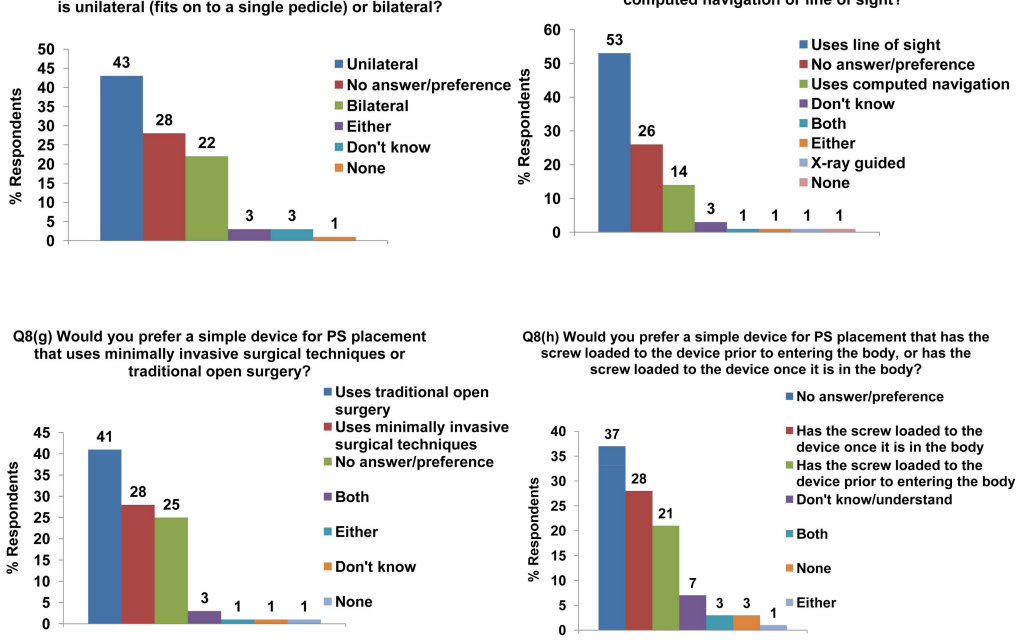

Fig. (3). Preferences for a simple device for PS placement (Question 8).

pedicles are larger and vary less. A pedicle aid was not seen as necessary, but may be useful in cases involving scoliosis, narrow pedicles, revision surgery and for "finding the pedicle when landmarks are lost/distorted."

\section{Sacral Region}

Respondents noted the need for a good foundation to lumbar/sacral fusion using long PSs; however, accurate screw placement was not seen as critical because of the large target area. An aid was favoured in this region for revision cases, tumours, "when landmarks are lost/distorted" and for "overweight patients, where the sacral region can be a difficult area to image."

\section{Q8. Preferences for a Simple Device for PS Placement}

This question consisted of 8 sub-questions that provided the answers in Fig. (3). There was no clear consensus in the answers given; however, if the majority opinion is taken for each of the design factors in Question 8, then the overall preference was for a device that is multiple use, one-piece, hand-held, radiolucent, unilateral and uses the line of sight principle in traditional open surgery, with no preference as to whether the PS should be loaded into the device before or after entering the body.
Q9. What Problems, if any, have you Experienced with PSs in Treating Patients with an Osteoporotic Spine?

Fig. (4) lists the problems encountered by the respondents whilst undertaking PS surgery in patients with an osteoporotic spine; these problems were already specified in the questionnaire and the respondents were asked to tick as many problems that were appropriate.

Q10. Historically, do you know of Any Screws that have been Designed for Osteoporotic Bone? If yes, Were these Screws Successful or Unsuccessful in Osteoporotic Bone?

The proportion of respondents that answered Yes to Question 10 was 27\%; the majority (70\%) did not know of any osteoporotic bone screws; 3\% did not answer Question 10 .

Respondents identified the Biomet ${ }^{\circledR}$ Omega21 ${ }^{\mathrm{TM}}$ Expandable Screw (Biomet UK Ltd., Bridgend, Wales) as being unsuccessful for fixation in osteoporotic bone and very difficult to revise. Some respondents noted the success of Ulrich Medical ${ }^{\circledR}$ articulated PSs (Ulrich GmbH \& Co.KG, Ulm, Germany), the Synthes ${ }^{\circledR}$ Universal Spine System (USS) II anterior screws (Synthes Ltd., Welwyn Garden City, Hertfordshire, UK), and the Ulrich Medical® tango 


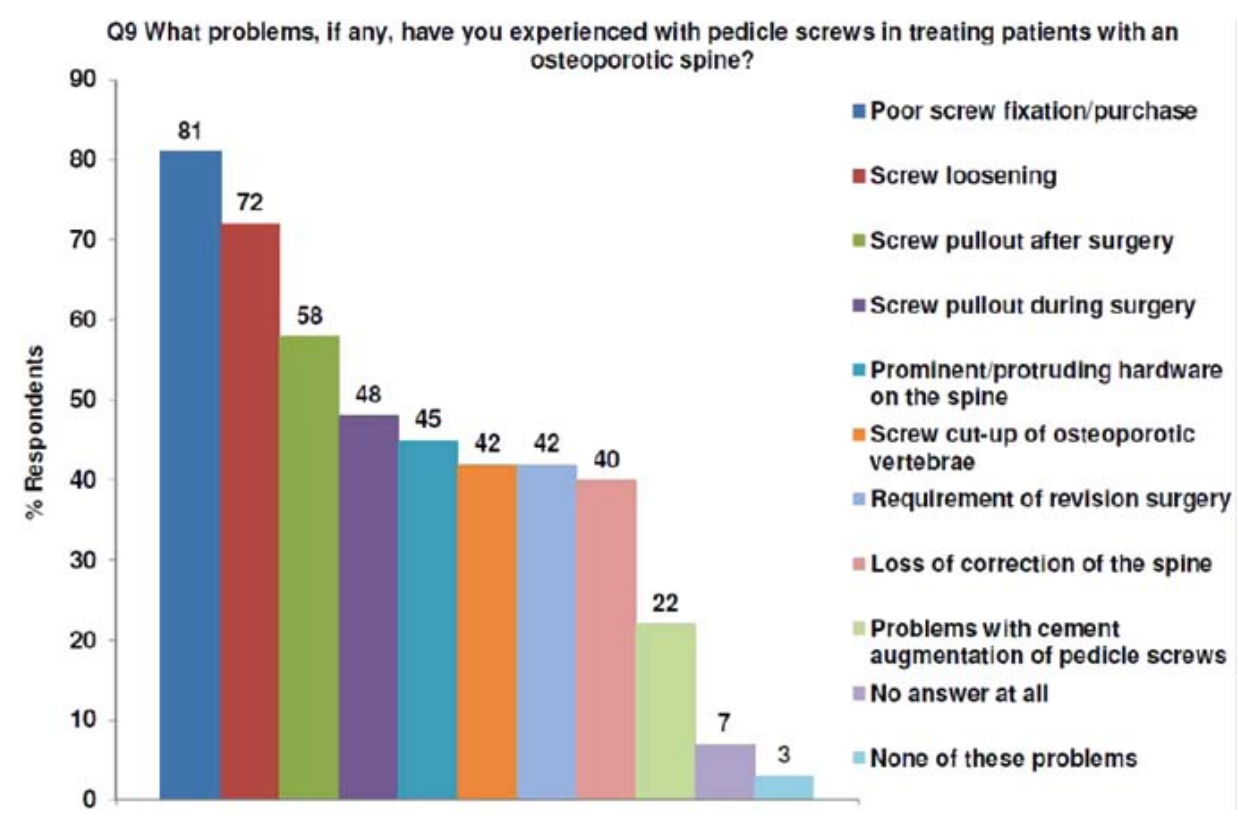

Fig. (4). Problems encountered by the questionnaire respondents whilst undertaking pedicle screw surgery in patients with an osteoporotic spine (Question 9).

RS $^{\text {TM }}$ system (Ulrich GmbH \& Co.KG, Ulm, Germany) for use in osteoporotic bone. Other successful screws for osteoporotic bone included hydroxyapatite-coated screws and hollow/cannulated screws to allow cement injection. One respondent noted that another approach "is to use long Schanz screws to engage the anterior cortex." Some respondents believed that screws designed for osteoporotic bone were very expensive and relatively unsuccessful.

Q11. Do you have Any other Suggestions or Opinions about PSs, Systems to Assist Spinal Surgery, the Design of a PS Placement Device or Osteoporosis in the Spine?

This question provided the opportunity for respondents to give any other opinions on PS surgery, which had not been previously covered in the questionnaire. Several responses consisted of statements that reinforced previous answers; these have been omitted from the following generalised list of final suggestions:

- Any proposed system should secondarily, not primarily, assist stability;

- Distal nail targeting devices should be considered;

- Pss may not have a long-term future.

\section{DISCUSSION}

\section{Complications Arising from Malpositioning}

The posterior-anterior approach for PS fixation is widely used. A large proportion of respondents have experienced problems arising from PS malpositioning (Table 2). The problems specified include breaching of the pedicle and vertebral body walls, pedicle fracture and various neurovascular impairments; these, and similar, problems have been identified previously [1,2]. Neurologic complications are generally considered the most serious, although some studies have stated that malpositioned PSs do not lead to compromised strength or long-term neuro-vascular impairment [3]. In a review of patients with PS plate fixation to the lumbar spine [11], nerve root impairment was noted in six out of fifty-seven patients, with all but two finally improving to normal. This suggests that only a minority of malpositioned PSs cause severe complications.

\section{Rationale for a Simple Device to Aid Placement}

The majority of respondents think there is a need for a simple device to aid PS placement, especially in the cervical and thoracic spine. The use of PSs in these regions is becoming more common [12]. In a Japanese survey, complications occurred in the cervical (10.3\%), thoracic $(13.5 \%)$ and lumbar $(6.7 \%)$ spine [12]. In a meta-analysis of PS placement, there was no advantage in using the existing navigation options in the thoracic spine [5]. It is important to note that surgeons should first, and foremost, rely on their anatomic and technical knowledge with regard to the accurate placement of PSs; any pedicle aid should only be considered as a supplementary tool during surgery.

Part of this questionnaire's aim was to determine the design criteria for a simple device to aid PS placement. The majority of respondents preferred a multiple use, one-piece, hand-held, radiolucent, unilateral pedicle aid that uses the line of sight principle in traditional open surgery, with no preference as to whether the PS should be loaded into the device before or after entering the body. Only $14 \%$ of respondents opted for a device that uses computed navigation. Also, 55\% of respondents do not use any systems to aid PS placement. These results are consistent with many surgeons being unhappy with computed navigation systems [13-15].

\section{PSs in Osteoporotic Bone}

The majority of respondents experience multiple problems with PS fixation in the osteoporotic spine, notably poor purchase, loosening and pullout. Several studies have reported on the increased pullout resistance of screws augmented with polymethylmethacrylate and various other bone cements in osteoporotic bone $[16,17]$. However, 22\% 
of respondents in this study still faced problems with the cement augmentation of PSs, which have been described previously [18].

Few successful screw designs appear to exist for osteoporotic bone; the majority of respondents were unfamiliar with screws specifically designed for osteoporotic bone. The reason for this could be that screw fixation is not always indicated for use in osteoporotic bone, although it has been performed [19]. Screw augmentation techniques involving injection of bone cement through a perforated screw may overcome some problems [20].

\section{Representation of Surgeons}

The 67 surgeons participating in this study were from a list of 422 surgeons provided by Surgicraft Ltd. (Redditch, UK). Whilst this list may introduce a potential selection bias, the authors believe that the list accounted for the majority of surgeons known to perform spinal surgery in the UK and Ireland. However, this list was not able to specify which surgeons actually perform PS surgery, which might explain the $24 \%$ response rate and why only $16 \%$ of the total questionnaires were completed and returned. The authors acknowledge that a higher response rate might have resulted in a more representative group of surgeons. As with all questionnaire studies, the data from the current study is limited by the response rate; it remains unclear whether these data truly reflect the opinions and preferences of the entire community of UK and Irish spine surgeons performing PS surgery. However, other surgical survey studies have generated responses in the range of $15-49 \%$ [2, 8-10] and many of these studies have used a much smaller survey group $[2,8,9]$.

\section{CONCLUSIONS}

This is a rare study, to our knowledge, in which the preferences for new devices to assist in the placement of PSs has been identified. Based on the experiences of 67 surgeons, there is evidence to suggest that computed navigational aids are not readily used in PS surgery and that a simple mechanical device could be a better option. We are unaware of previous studies that have examined the current practice of PS surgery in the UK and Ireland; this paper provides useful data for improving the outcomes of spinal surgery through improvements in surgical procedures.

\section{ACKNOWLEDGEMENTS}

The authors would like to thank the surgeons that participated in this study, Surgicraft Limited for financial support and the School of Mechanical Engineering, University of Birmingham, for providing a studentship for PSDP.

\section{REFERENCES}

[1] N. Boos, and J.K. Webb, "Pedicle screw fixation in spinal disorders: A European view," Eur spine J, vol. 6, pp. 2-18, 1997.

[2] S.I. Esses, B.L. Sachs, and V. Dreyzin, "Complications associated with the technique of pedicle screw fixation - A selected survey of ABS members," Spine, vol. 18, pp. 2231-2239, 1993.

[3] C.J. Schulze, E. Munzinger, and U. Weber, "Clinical relevance of accuracy of pedicle screw placement - A computed tomographicsupported analysis," Spine, Vol. 23, pp. 2215-2220, 1998.

[4] H.N. Modi, S.W. Suh, H. Fernandez, J.H. Yang, and H-R. Song, "Accuracy and safety of pedicle screw placement in neuromuscular scoliosis with free-hand technique," Eur Spine J., vol. 17, pp. 16861696, 2008.

[5] V. Kosmopoulos, and C. Schizas, "Pedicle screw placement accuracy - A meta-analysis,” Spine, vol. 32, pp. E111-E20, 2007.

[6] A. Nowitzke, M. Wood, and K. Cooney, "Improving accuracy and reducing errors in spinal surgery - A new technique for thoracolumbar-level localization using computer-assisted image guidance," Spine J., vol. 8, pp. 597-604, 2008.

[7] M. Bland, An introduction to medical statistics. 3rd ed. Oxford: Oxford University Press, 2000.

[8] P. Leece, M. Bhandari, S. Sprague, M.F. Swiontkowski, E.H. Schemitsch, and P. Tornetta, "Does flattery work? A comparison of 2 different cover letters for an international survey of orthopedic surgeons," Can. J. Surg., vol. 49, pp. 90-95, 2006.

[9] M.P. Glotzbecker, C.M. Bono, M.B. Harris, G. Brick, R.F. Heary, and K.B. Wood, "Surgeon practices regarding postoperative thromboembolic prophylaxis after high-risk spinal surgery," Spine, vol. 33, pp. 2915-2921, 2008.

[10] A. Matarasso, A. Elkwood, M. Rankin, and M. Elkowitz, "National plastic surgery survey: Face lift techniques and complications," Plast. Reconstr. Surg., vol. 106, pp. 1185-1195, 2000.

[11] H. Matsuzaki, Y. Tokuhashi, E. Matsumoto, M. Hoshino, T. Kiuchi, and S. Toriyama, "Problems and solutions of pedicle screw plate fixation of lumbar spine," Spine, vol. 15, pp. 1159-1165, 1990.

[12] Y. Nohara, H. Taneichi, K. Ueyama, N. Kawahara, K. Shiba, Y. Tokuhashi, T. Tani, S. Nakahara, and T. Iida, "Nationwide survey on complications of spine surgery in Japan," J. Orthop. Sci., vol. 9, pp. 424-433, 2004.

[13] L.T. Holly, and K.T. Foley, "Intraoperative spinal navigation," Spine, vol. 28, pp. S54-S61, 2003.

[14] L.T. Holly, "Image-guided spinal surgery," Int. J. Med. Robot., vol. 2, pp. 7-15, 2006.

[15] P. Grunert, K. Darabi, J. Espinosa, and R. Filippi, "Computer-aided navigation in neurosurgery," Neurosurg. Rev., vol. 26, pp. 73-99, 2003 .

[16] D.J. Burval, R.F. McLain, R. Milks R, and S. Inceoglu, "Primary pedicle screw augmentation in osteoporotic lumbar vertebrae Biomechanical analysis of pedicle fixation strength," Spine, vol. 32, pp. 1077-1083, 2007.

[17] J.C. Lotz, S.S. Hu, D.F.M. Chiu, M. Yu, O. Colliou, and R.D. Poser, "Carbonated apatite cement augmentation of pedicle screw fixation in the lumbar spine," Spine, vol. 22, pp. 2716-2723, 1997.

[18] R.A. Wilkes, J.G. Mackinnon and W.G. Thomas, "Neurological deterioration after cement injection into a vertebral body," J. Bone Joint Surg. Br., Vol. 76B, pp. 155, 1994.

[19] P.F. Heini, "The current treatment - A survey of osteoporotic fracture treatment. Osteoporotic spine fractures: the spine surgeon's perspective," Osteoporos. Int., vol. 16, no. 2, pp. S85-S92, 2005.

[20] S. Becker, A. Chavanne, R. Spitaler, K. Kropik, N. Aigner, M. Ogon and H. Redl, "Assessment of different screw augmentation techniques and screw designs in osteoporotic spines," Eur. Spine J., vol. 17, pp. 1462-1469, 2008.

\footnotetext{
Received: June 26, 2011
}

(C) Patel et al.; Licensee Bentham Open.

This is an open access article licensed under the terms of the Creative Commons Attribution Non-Commercial License (http://creativecommons.org/licenses/by-nc/3.0/) which permits unrestricted, non-commercial use, distribution and reproduction in any medium, provided the work is properly cited. 